\section{Comparison of maloclusion prevalence in Elementary School children with different economic levels (case study in SDN Inpres Kera-Kera and SDIT Al-Biruni Makassar)}

\author{
Ardiansyah S. Pawinru, ${ }^{*}$ Muhammad IA. Bahar
}

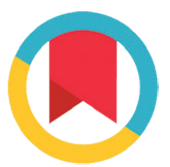

CrossMark

Abstract

Objective: To determine the comparison of the prevalence of malocclusion between elementary school children with high economic level and low economic level.

Material and Methods: The subjects of this study were students of Kera-Kera Inpres Elementary School and Al-Biruni Makassar SDIT. This type of research is a descriptive observational cross-sectional design by purposive sampling to 103 students. Research subjects will be given a questionnaire and then examined the oral cavity and photographs.
Results: In this study subjects, the prevalence of malocclusion was higher in Al-Biruni Makassar SDIT (81.4\%) compared to the Kera-Kera Inpres Elementary School (63.6\%). Statistical analysis of the Mann-Whitney comparison test values obtained $p=0.072$ ( $p>0.05)$.

Conclusion: There is no significant difference in prevalence between SD Inpres Kera-Kera and SDIT AI-Biruni Makassar.
Department of Orthodontic, Faculty of Dentistry, Hasanuddin University, Makassar, Indonesia
*Correspondence to:

Ardiansyah S. Pawinru, Department of Orthodontic, Faculty of Dentistry, Hasanuddin University, Makassar, Indonesia pawinru190879@gmail.com

Received: 5 January 2021 Revised: 17 March 2021 Accepted: 25 July 2021 Available Online: 1 August 2021

Keywords: Economic level, Malocclusion, Significant difference

Cite this Article: Pawinru AS, Bahar MIA. 2021. Comparison of maloclusion prevalence in Elementary School children with different economic levels (case study in SDN Inpres Kera-Kera and SDIT Al-Biruni Makassar). Journal of Dentomaxillofacial Science 6(2): 110-113. D0I: 10.15562/jdmfs.v6i2.1239

\section{Introduction}

Health is an asset in life that we must always look after including oral health. Teeth play a role in the process of mastication, speech and appearance. Various diseases and abnormalities of teeth and mouth can affect various oral cavity functions. One of them is an abnormality in the arrangement of teeth or called malocclusion. ${ }^{1}$

Malocclusion is an abnormal occlusion characterized by improper relationship between dental arches or anomalies in tooth position. ${ }^{2}$ In Indonesia itself, malocclusion is an important issue in the field of dental health. ${ }^{3}$ Based on the 2013 National Basic Health Research (Riskesdas) report 14 provinces experienced dental and mouth problems which was $25.9 \%$. The prevalence of malocclusion in Indonesia is still very high, around 80\% of the population, and is one of the major oral and dental health problems. ${ }^{4}$

The etiology of malocclusion is multifactorial. ${ }^{5}$ The occurrence of malocclusion is strongly influenced by hereditary factors inherited from parents and environmental factors such as bad habits and eating patterns. ${ }^{6}$ In addition to heredity and bad habits, malocclusion can also be influenced by one's social character including economic level family. ${ }^{5}$ Healthy living behavior can be influenced by someone's socioeconomic. ${ }^{7}$
Individuals who have an income above the Regional Minimum Wage (UMR) tend to pay more attention to the quality of health services so that they will choose high-quality health services, such as Hospitals. ${ }^{8}$ Low income earners limit themselves from making visits to dental health service units. ${ }^{9}$ People with low incomes rarely pay a visit to the dentist, which makes them less familiar with their insights into dental health. ${ }^{10}$

Research conducted by Normando in 2015, reported that a person's socioeconomic level affected the incidence of malocclusion in primary teeth. In the largest regions in the Amazon region, 1 in 5 children with low socioeconomic status had at least one tooth before they reached 7 years of age. ${ }^{11}$ Another 2002 study conducted by Silva reported a risk of more malocclusions high in children attending public schools (low socioeconomic status). This study also found a higher prevalence of anterior open bite and bad habits in children with low socioeconomic status. ${ }^{12}$ In line with research conducted in Venezuela by Moron in 1997, children in public schools had a prevalence of deciduous teeth early on which is much higher. ${ }^{13}$

\section{Material and Methods}

This research was an observational descriptive study with a cross sectional study design. Tools 


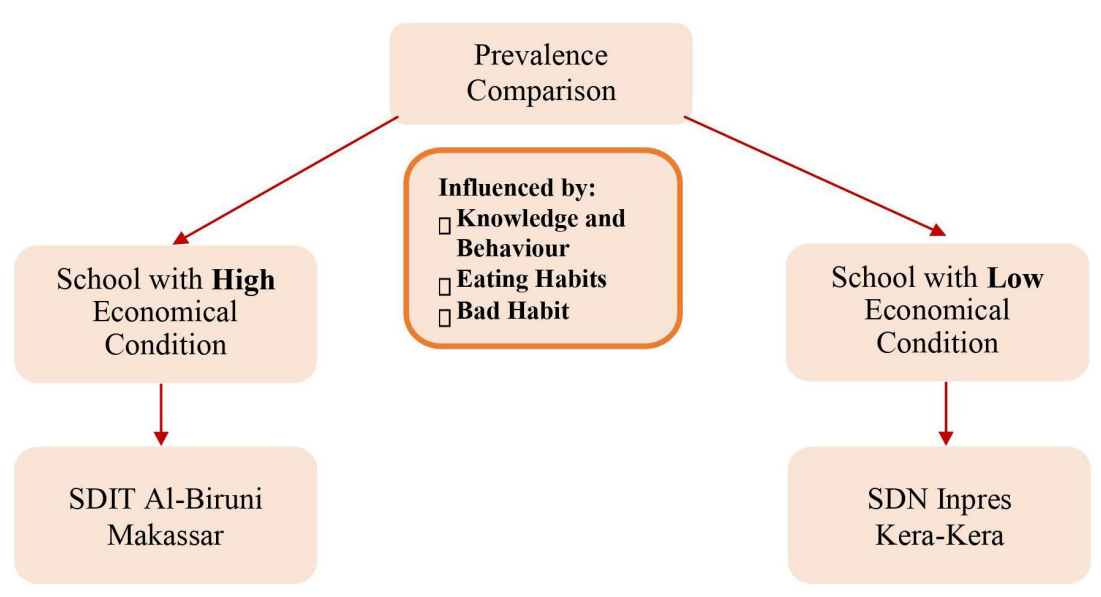

Figure 1 Concept structure

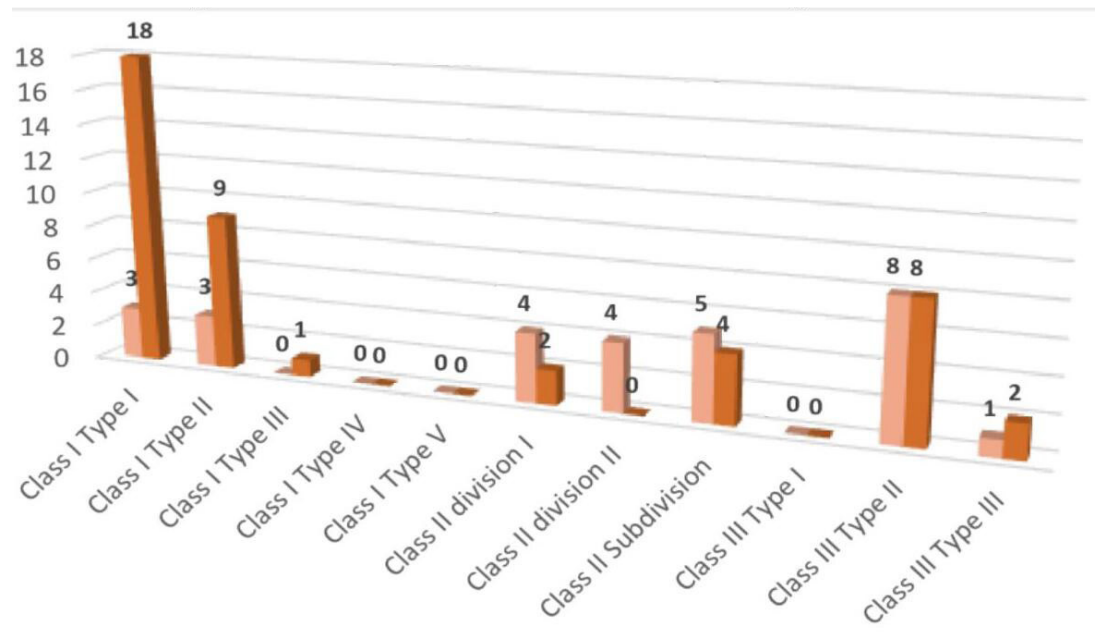

m SDN Inpres Kera-Kera $\quad$ SDIT Al-Biruni Makassar

Figure 2 Malocclusion Prevalence in SDIT Al-Biruni Makassar and SDN Inpres Kera-Kera

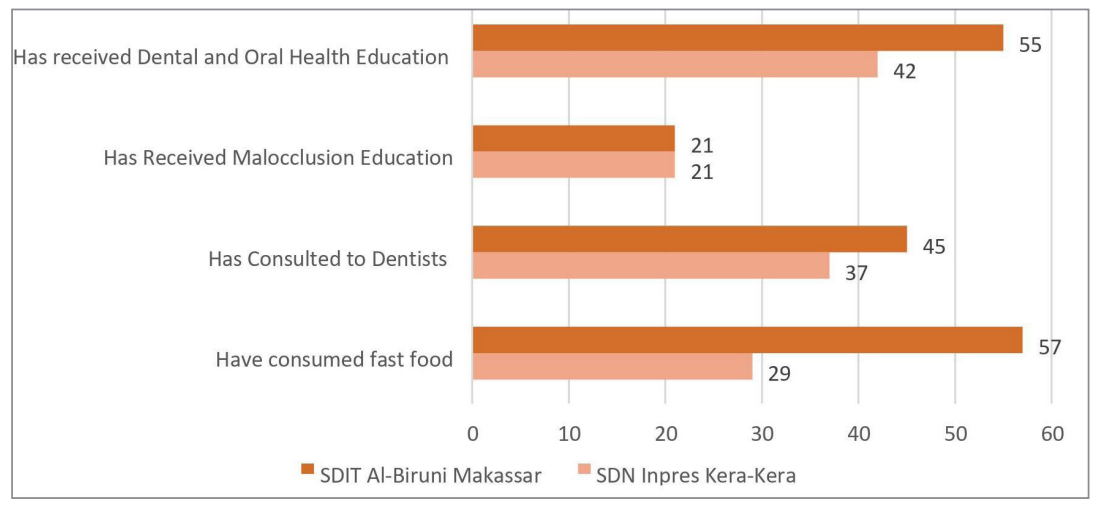

Figure 3 Level of Knowledge and Behavior of Research Subjects

and materials used are stationery, masks, handsets, mouth mirror, and bulkhead tray. Meanwhile, for taking extra oral and intra oral photographs of children who are the subjects of the study, the tools used are the cheek retractor and the camera.
The study was conducted by purposive sampling to school students with low economic level (KeraKera Inpres Elementary School) and schools with high economic level (SDIT Al-Biruni) Makassar with inclusion criteria aged 9-12 years and had never received orthodontic treatment. Exclusion criteria are students who have experienced maxillofacial trauma and children who have abnormalities in the number or shape of the teeth.

Children who are the subjects of the study will be given a questionnaire that asks about the level of knowledge, attitudes of children, and lifestyles associated with the occurrence of malocclusion. Furthermore, the oral cavity was examined by looking at the presence or absence of malocclusion events followed by taking extra oral and intra oral photographs on the study subjects figure 1 .

\section{Results}

Based on research conducted at Kera-Kera Inpres Elementary School and Al-Biruni Makassar SDIT, the following malocclusion events were compared.

Figure 2 shows the prevalence rate based on the classification of Angle in the Kera Kera Inpres Elementary School of 28 people (63.6\%) with a class I type I malocclusion classification of 3 people (6.8\%), class I type II 3 people (6.8\%), class II division I 4 people (9.1\%), class II division II 4 people (9.1\%), class II subdivisions 5 people (11.4\%), class III type II 8 people (18.2\%), and class III type III 1 person $(2.3 \%)$. In the research Kera Kera Inpres Elementary School, there were no students who experienced class I type III malocclusions, class I type IV, class I type V, and class III type I.

While at SDIT Al-Biruni Makassar as many as 48 people $(81.4 \%)$ with the distribution of class I malocclusion class I type 18 people (30.5\%), class I type II 9 people (15.3\%), class I type III 1 person (1.7\%), class II division I 2 people (3.4\%), class II subdivisions 4 people (6.8\%), class III type II 8 people (13.6\%), and class III type III 2 people (3.4\%). Practically, we can see that the prevalence of malocclusion is higher in SDIT Al-Biruni Makassar (81.4\%) compared to Kera Kera Inpres Elementary School (63.6\%). Statistics using the Mann-Whitney test showed no significant difference in prevalence rates between Kera Kera Inpres Elementary School and Al-Biruni Makassar SDIT ( $\mathrm{p}>0.05$ ).

Based on figure 3, the number of students in the Kera Kera Inpres Elementary School that has received Dental and Oral Health Education is 42 people (95.5\%), Has Received Malocclusion Education by 21 people (47.7\%), Has Consulted 37 Dentists (84.1) \%, and 29 people have consumed fast food $(65.9 \%)$. 


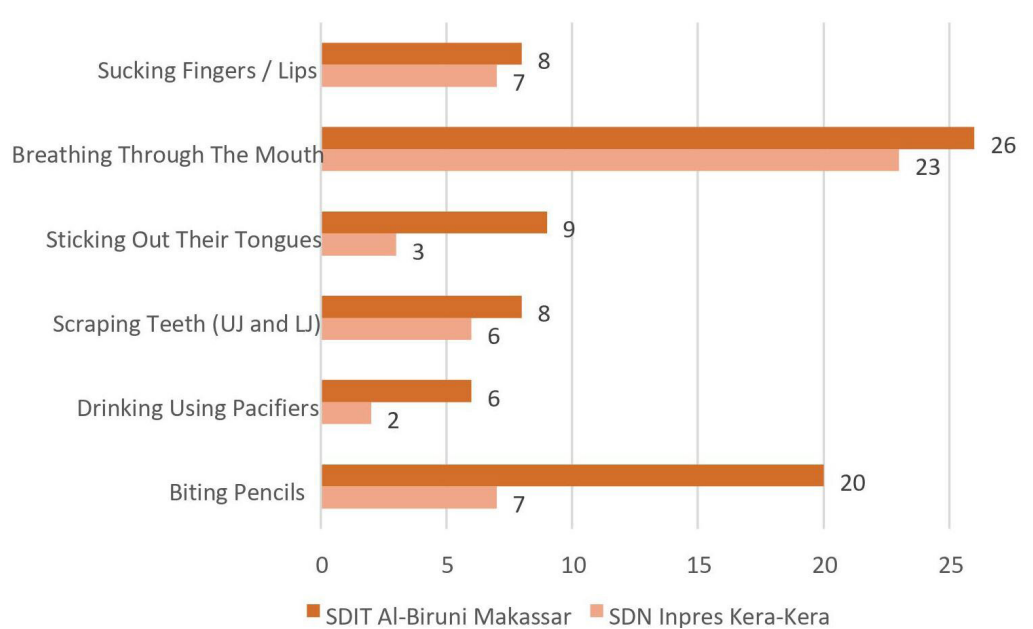

Figure 4 Bad Habits of Reasearch Subjects

While students at SDIT Al-Biruni Makassar who had received oral and dental health education were 55 people (93.2\%), had received Malocclusion Education as many as 21 people (35.6\%), had 45 dental consultants (76.3\%), and Ever consumed fast food as many as 57 people (96.6\%).

It can be seen in figure 4 the number of students of Kera Kera Inpres Elementary School who have bad habits in the form of sucking fingers / lips are as many as 7 people (15.9\%), breathing through the mouth 23 people $(52.3 \%)$, sticking out their tongues 3 people $(6.8 \%)$, Scraping teeth Upper Jaw and Lower Jaw (UJ and LJ) 6 people (13.6\%), Drinking using pacifiers 2 people (4.5\%), and Biting pencils / nails 7 people (15.9\%). While the number of students of SDIT Al-Biruni Makassar who have bad habits in the form of sucking fingers / lips is as many as 8 people (13.6\%), breathing through the mouth 26 people (44.1\%), sticking out the tongue 9 people (15.3\%), rubbing teeth RA and RB 8 people (13.6\%), Drinking using pacifiers 6 people $(10.2 \%)$, and Biting pencils / nails 20 people (33.9\%).

\section{Discussion}

The etiology of malocclusion is multifactorial. ${ }^{4}$ In addition to heredity and bad habits, malocclusion can also be influenced by a person's social character including the level of the family economy. ${ }^{4}$ Normando's study of 652 children in Brazil in 2015, girls at the level high socioeconomic has a higher prevalence than women at low socioeconomic level at $84.7 \%$ compared to $72.1 \% .^{11}$ Normando also reported that the prevalence of class II malocclusion in research subjects was $67.5 \%$ and was more dominated by students with high economic levels.

In contrast to research by Silva in 2002 which reported a higher risk of malocclusion in children who attend public schools (low socioeconomic status) than private schools (high socioeconomic status). The study also found a higher prevalence of anterior open bite and bad habits in children with low socioeconomic status. As we know that bad oral habits can cause malocclusion. In line with research conducted in Venezuela by Moron in 1997, children in public schools had a much higher prevalence of early date deciduous teeth. Early date deciduous teeth can have implications for the abnormal movement of neighboring teeth and also antagonistic teeth which can later cause malocclusion. From the literature review we have done, there is no significant relationship between a person's economic condition and the incidence of malocclusion.

On the subject of this study, data were obtained that the prevalence of malocclusion was higher in Al-Biruni Makassar SDIT (81.4\%) compared to the Kera Kera Inpres Elementary School (63.6\%). Statistics using the Mann-Whitney test showed no significant difference in prevalence rates between Kera-Kera Inpres Elementary School and Al-Biruni Makassar SDIT ( $p>0.05)$. Data from the questionnaire explained that in general students at KeraKera Elementary Inpres had better knowledge and behavior compared to SDIT Al-Biruni Makassar. The number of students who have acquired oral and dental health knowledge, knowledge of malocclusion and who have consulted dentists in a row is greater at Kera-Kera Inpres Elementary School (95.5\%, $47.7 \%$ and $84.1 \%$ ) compared to Al-Biruni Makassar SDIT (93.2\%, 35.6\% and 76.3\%). It was also found that the number of students who had bad mouth breathing habits was greater in the KeraKera Inpres Elementary School (52.3\%) compared to Al-Biruni Makassar SDIT (44.1\%). Statistical analysis of the Chi-Square test on Al-Biruni SDIT students showed a significant relationship between bad mouth breathing habits and the prevalence of malocclusion $(\mathrm{p}=0.007)$.

Based on the questionnaire that the researchers gave to the subjects, it was found that students in the Kera Kera Inpres Elementary School as much as $34.1 \%$ of the sample had never consumed fast food and this was different from students in the SDIT Al-Biruni Makassar who had dominantly consumed fast food with a percentage of $96.6 \%$ from the sample. Also found students at the KeraKera Inpres Elementary School tend to consume vegetables and fish. This data is consistent with Ausin and Hamid's research in 2017 that the frequency of groups who consume hard food every day is very significant with almost $40 \%$ of students not experiencing malocclusion, while the group of students who rarely consume hard foods with $4.4 \%$ mild malocclusion, $3.2 \%$ moderate, and 
2.6\% severe. Harder foods are adapted from oral health and nutrition guidelines based on local, cultural, economic, and food choices. Children in low economic circles consume hard foods such as vegetables and wheat every day and consume very little soft food due to ability and affordability issues, while children who are in higher economic circles consume soft food which results in underdeveloped craniofacial structure due to reduced use of the power of mastication which then reduces the involvement of jaw function. ${ }^{14}$

\section{Conclusion}

From this study it can be concluded that there is no significant difference in prevalence between KeraKera Inpres SD and Al-Biruni Makassar SDIT with a Mann-Whitney comparison test value $\mathrm{p}=0.072$ ( $p>0.05$ ). The etiology of malocclusion is multifactorial including one's economic level as a supporting factor for malocclusion, so a deeper analysis is needed to obtain a clear relationship between the causative factors and the occurrence of malocclusion itself and minimize existing confounding variables.

\section{Acknowledgment}

Thank you for the support Faculty of Dentistry Hasanuddin University.

\section{Conflict of Interest}

The authors report no conflict of interest.

\section{References}

1. Laguhi VA, Anindita PS, Gunawan PN. Description of maloclusion using hmar in patients at the Dental Hospital, Sam Ratulangi University, Manado. J e-Gigi 2014;2: 12. (In Indonesia)
2. Bakri FF, Kurniawati D, Suyadi. Differences in the width of the dental arch in angle classification malocclusion at SMPN 1 Salatiga, Central Java. Kedokteran Gigi Universitas Muhammadiyah; Surakarta: 2015. p. 3. (In Indonesia)

3. Kumar DA, Varghese RK, Chaturvedi SS, et al. Prevalence of malocclusion among children and adolescents residing in orphanages of Bilaspur, Chattishgarh, India. J Adv Oral Res 2012;3: 21-28.

4. Akbari M, Lankarani KB, Honarvar B, et al. Prevalence of malocclusion among Iranian children: A systematic review and meta-analysis. J Dent Res. 2016;13:387-395.

5. Wijayanti P, Krisnawati, Ismah N. Overview of malocclusion and the need for orthodontic treatment in children aged 9-11 years (Preliminary study at SD At-Taufiq, Cempaka Putih, Jakarta). J PDGI 2014;63: 25-29. (In Indonesia)

6. Mulder BC, Marijn DB, Hanneke S, et al. Stressors and resources mediate the associationofsocio-economic position with health behavior. BMC Public Health 2011;11: 798.

7. Newman JF, Gift HC. Regular pattern of preventive dental services - A measure of access. Soc Sci Med 1992;35: 997-1001.

8. Sanders AE, Slade GD, Turrell G, et al. The shape of the socioeconomic-oral health gradient: Implications for theoretical explanations. Community Dent Oral Epidemiol 2006;34: 310-319.

9. Normando TS, Barroso RF, Normando D. Influence of the socioeconomic status on the prevalence of malocclusion in the primary dentition. Dental Press J Orthod 2015;20: 74-78.

10. Silva OG, Filho, Silva PRB, et al. Epidemologia da má oclusão da dentadura decídua. Ortodontia 2002;25: 22.

11. Morón $\mathrm{AB}, \mathrm{Baez} \mathrm{A}$, Rivera L, et al. Perfil de la oclusion Del ninõ en edad preescolar. Factores de beneficio y riesgo. Acta Odontol Venez 1997;35: 12.

12. Ausin S, Hamid S. Status of malocclusion in 9-12-year-old children: A survey among private and public schools of islamabad. J Med Res Health Educ 2017;1: 1-6.

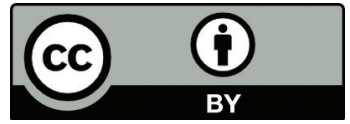

This work is licensed under a Creative Commons Attribution 